\title{
O Tornar-se Avó no Processo de Individuação ${ }^{1}$
}

\author{
Caroline Dal Ri Kipper \\ Rita Sobreira Lopes ${ }^{2}$ \\ Universidade Federal do Rio Grande do Sul
}

\begin{abstract}
RESUMO - O tornar-se avó assinala um período de transição no ciclo de vida familiar, marcado por transformações psíquicas significativas para os avós, caracterizando a quarta individuação. Este trabalho teve como objetivo investigar a experiência de tornar-se avó e sua importância no processo de individuação. Foi utilizado delineamento de estudo de caso coletivo. Onze avós maternas, com idades entre 49 e 66 anos, cujas filhas tiveram seu primeiro filho, responderam a uma entrevista semi-estruturada. Todas as avós tinham tido seus primeiros netos e a entrevista referia-se a sua experiência como avós desses netos. Os dados mostraram que o ser avó é uma fonte de renovação e renascimento. O estudo propiciou que as participantes refletissem sobre seus diferentes papéis familiares: avó, mãe, neta e filha. Os dados sugerem que tornar-se avó possibilita que antigos conflitos sejam repensados, renovando antigos vínculos e desejos, o que permite que a avó dê mais um passo rumo à sua individuação.
\end{abstract}

Palavras-chave: tornar-se avó; individuação; ciclo de vida familiar.

\section{Becoming a Grandmother in the Individuation Process}

\begin{abstract}
Becoming a grandmother points out a transition period in the family life cycle, marked by significant psych transformations for the grandmothers, characterizing the fourth individuation. This study aimed at investigating the experience of becoming a grandmother and its importance in the individuation process. A collective case study design was used. Eleven grandmothers, aged 49 to 66, whose daughters had their first child, answered a semi-structured interview. All grandmothers had had their first grandchildren and the interview referred to their experience as grandmothers of these grandchildren. The results showed that being a grandmother is a source of renewal and rebirth. The study enabled the participants to reflect on their different family roles: grandmother, mother, grandchild and child. The data suggest that becoming a grandmother enables old conflicts to be re-thought, renewing old ties and desires, and as a result, enabling the grandmother to give one more step towards her individuation.
\end{abstract}

Key words: becoming a grandmother; individuation; family life cycle.

O momento em que nasce um neto marca a passagem para uma outra fase no ciclo de vida familiar, que traz algumas modificações, não só na estrutura familiar, como na estrutura psíquica dos novos avós - uma nova identidade tem de ser criada, novos papéis adquiridos. Apesar da importância deste momento no desenvolvimento adulto, chama a atenção a ausência de estudos focalizando o tornar-se avós nos seus aspectos evolutivos, em especial sua importância no processo de individuação, foco do presente estudo.

Na literatura psicanalítica, há uma extensa literatura sobre o processo de separação e individuação na infância e na adolescência, mas há ainda pouco sobre o processo de separação e individuação no adulto (Colarusso, 1990). O processo de individuação tem seu início na diferenciação da criança de sua mãe, de sua natureza simbiótica, com a perda do objeto materno, o que caracteriza a primeira individuação (Mahler, 1982).

1 Trabalho baseado na Dissertação de Mestrado da primeira autora sob supervisão da segunda autora. As autoras agradecem o apoio do CNPq.

2 Endereço: Universidade Federal do Rio Grande do Sul, Rua Ramiro Barcelos, 2600/108, Porto Alegre, RS, Brasil 90035-003. E-mail: carolkipper@bol.com.br; sobreiralopes@portoweb.com.br
A segunda individuação acontece, segundo Colarusso (1990), na adolescência. Blos (1994) foi o autor psicanalítico que se dedicou a este momento evolutivo, em que o jovem revive suas relações primitivas com seus pais, necessitando de um trabalho psíquico bastante doloroso, que corresponde à separação e diferenciação das imagens internalizadas dos mesmos.

A terceira individuação acontece com a experiência de parentalidade (Colarusso, 1990). O novo papel assumido com a parentalidade expande o self adulto e estimula a separação de seus próprios pais. Ao tornar-se pais, um novo papel é assumido, até então exclusivo ao território dos progenitores, emergindo um novo senso de paridade. É inevitável a comparação dos novos pais, consciente ou inconsciente, com a criação que tiveram de seus pais.

A quarta individuação se dá quando o indivíduo se torna avó ou avô (Colarusso, 1990). Os avós, no momento em que seus filhos tornam-se pais, precisam redefinir a nova posição que irão ocupar entre as gerações, e devem alterar a representação de seu filho e desenvolver novos vínculos com o neto. Assim, os avós, que estão resolvendo tarefas da meia-idade, como aposentadoria, doença, perda do cônjuge, direcionam sua atenção para essa criança que acaba de chegar e que representa o futuro genético deles mesmos, um futuro que irá permanecer, mesmo após suas mortes. 
De acordo com Colarusso (1997), a aceitação das inevitáveis separações e perdas, que acompanham a independência, é a tarefa desenvolvimental central do adulto de meia-idade. Outro fato é estar face-a-face com a morte. $\mathrm{O}$ autor sugere que a preocupação com a consciência de sua morte é um poderoso organizador psíquico que força a um exame significativo de todas as experiências passadas e também influencia fortemente o processo de separação-individuação. Outras tarefas seriam manter a intimidade, transformar a relação com os filhos e integrar novos membros à família, tornar-se avós, ter cuidados com a idade e a morte dos pais, e construir e manter amizades. $\mathrm{O}$ autor também destaca que a autonomia e a independência de seus filhos estimula os pais a se separarem deles.

$\mathrm{O}$ vínculo com os netos é algo bastante particular, pois os avós tendem a idealizá-los. A idealização intensa e investimento nos netos servem como uma defesa contra as aflições da idade avançada e a morte inevitável, assim como uma chance mágica de reparar sua própria vida, através da imortalidade genética, e como uma recusa às imperfeições do self, através de uma identificação seletiva com qualidades dos netos (Colarusso, 1997).

Para Robinson (1989), os avós que têm um bom relacionamento com seus filhos adultos e com os cônjuges de seus filhos têm maior probabilidade de desenvolver uma relação gratificante com seus netos. A autora também propõe que os netos utilizam seus avós como objetos para identificação, pois unem suas próprias histórias e são uma fonte de prazer. Os avós, por sua vez, têm outra oportunidade de resolver a crise da meia-idade, ajudando os netos a superar suas crises evolutivas. Hader (1965) também afirma que a sensibilidade e o entendimento que os avós têm ao lidar com seus netos podem fornecer um modelo de identificação para estes.

O tornar-se avós traz muitas possibilidades para estes sujeitos e uma nova etapa para toda a família, pois abrange uma geração a mais. Do ponto de vista das avós, Dias (1994) ressaltou que a chegada de um neto para a mulher de meia-idade pode ser uma solução, por ter "perdido" seus filhos através do casamento. Assim, a avó adquire uma nova importância e utilidade, experenciando de uma outra forma ser mãe novamente, mas sem as responsabilidades que tinha quando foi mãe. A existência de netos pode também contribuir para a melhoria na qualidade do relacionamento entre pais e seus filhos (Lidz, 1983).

Ao revisar a literatura sobre os avós não foram encontrados estudos que tenham investigado o tornar-se avós como marco evolutivo importante do desenvolvimento adulto. Os estudos enfocam predominantemente as avós como cuidadoras ou figuras de apoio. Desta forma, o presente trabalho busca preencher uma lacuna, ao analisar um aspecto evolutivo do tornar-se avó, o processo de individuação. O estudo teve como foco as avós maternas, já que a literatura aponta um envolvimento mais intenso das avós maternas com os netos (Fischer, 1983; Barros, 1987; Dias, 1994; Somary \& Stricker, 1998). Visto que este momento é bastante peculiar e traz grandes modificações, espera-se realizar uma descrição dos aspectos mais importantes no tornar-se avó, com um confronto entre quatro papéis (avó, mãe, neta, filha), inerentes ao processo de desenvolvimento na quarta individuação (Colarusso, 2000).

\section{Método}

\section{Participantes}

Participaram do estudo 11 avós maternas, cujas filhas estavam tendo seu primeiro filho e elas, o primeiro neto. Tinham idades entre 49 e 66 anos (média de 56 anos) e os netos, entre 3 e 4 anos, na época da entrevista. Sete participantes eram casadas, três viúvas e uma solteira. As profissões variaram, sendo que cinco participantes eram do lar, três eram professoras aposentadas, uma advogada, uma telefonista aposentada, uma comerciária e uma contadora aposentada. $\mathrm{O}$ nível escolar variou desde o Ensino Fundamental Incompleto (duas participantes), passando pelo Ensino Fundamental Completo (uma participante), Ensino Médio Incompleto (duas participantes), Completo (quatro participantes) e Ensino Superior (duas participantes). O número de filhos também variou, sendo que oito participantes tinham dois filhos, duas uma filha e uma tinha três filhos. O número de netos variou de um (sete participantes) a dois netos (quatro participantes). A maioria das participantes (seis) morava em Porto Alegre, três moravam na Região Metropolitana e duas no Litoral Gaúcho. Duas moravam com o neto.

A amostra foi selecionada a partir dos participantes do "Estudo Longitudinal de Porto Alegre: Da gestação à Escola" (Piccinini, Tudge, Lopes \& Sperb, 1998), o qual foi aprovado pelo Comitê de Ética em Pesquisa do Hospital de Clínicas de Porto Alegre. Participam do estudo aproximadamente uma centena de famílias com várias configurações familiares (casadas, recasadas, solteiras), de diferentes idades (jovens e adultos), com escolaridades e níveis sócio-econômicos variados.

\section{Delineamento e procedimentos}

Foi utilizado neste estudo o delineamento de estudo de caso coletivo (Stake, 1994), de caráter exploratório. Este estudo teve por objetivo identificar as mudanças ocorridas nas participantes após tornarem-se avós.

Inicialmente, foi realizado contato telefônico com as avós, em que se explicava sucintamente a pesquisa e elas eram, então, convidadas a participar, sendo agendada uma entrevista domiciliar. Com as avós que tinham esposos também era marcada uma entrevista com eles no mesmo instante, ou seja, uma pesquisadora e uma bolsista iam até a residência do casal e as entrevistas eram realizadas com os dois em separado, no mesmo momento, para que não houvesse interferência de um no outro. Nenhuma das avós se recusou a participar do estudo. As entrevistas com os avôs não fizeram parte do presente estudo.

\section{Instrumentos}

O Consentimento Livre e Esclarecido (GIDEP, 1998) foi assinado, no qual os participantes se declaravam cientes da sua participação na pesquisa, dando início, dessa forma, à coleta de dados. Em seguida, eram preenchidos os dados demográficos e pessoais. Posteriormente, era realizada a Entrevista com avô e avó (Kipper \& Lopes, 2002), que abordava temas referentes ao tornar-se avó. Incluía aspectos 
da vida pessoal dos avós, reflexões sobre o momento em que se tornaram avós, bem como todas as mudanças que ocorreram desde então e em função de sua nova condição de avós. Também era investigada a relação com a filha, antes e depois de ela ter tido um filho.

A infância dos participantes era relembrada, quando era abordada a relação com os próprios avós, e o último tópico relacionava-se ao envolvimento com os pais, especialmente quando estes se tornaram avós e quando a participante teve o primeiro filho. Cada tópico investigado era apresentado inicialmente às avós em forma de uma questão ampla (ex: Gostaria que a senhora me falasse um pouco sobre o momento em que soube que ia ser avó). Caso a resposta da avó não fosse muito explícita, eram então usadas outras questões que ajudavam a esclarecer os tópicos investigados (ex: Como a senhora recebeu a notícia de que ia ser avó? Neste momento a senhora já estava pensando na idéia de ser avó?).

\section{Resultados}

Análise de conteúdo (Bardin, 1977; Laville \& Dione, 1999) foi utilizada para se examinar o tornar-se avó e o processo de individuação. Para fins de análise, os dados das entrevistas foram agrupados em quatro eixos temáticos: Experiência como Avó, Experiência como Mãe, Experiência como Neta e Experiência como filha. Em cada um destes eixos, buscou-se o entendimento de como vivenciou cada papel, e seus novos significados em função de ter se tornado avó, assim como a nova possibilidade de resolução de antigos conflitos e desejos. Assim, o Eixo I, Experiência como Avó, buscou explicitar como se deu a experiência de tornar-se avó. O Eixo II, Experiência como Mãe, teve por objetivo analisar em que medida o fato de ter um neto fez a avó reviver sua experiência como mãe, ao ter a própria filha. Já o Eixo III, Experiência como Neta, tratou da vivência das mulheres como netas, e como isso repercute agora em que também são avós. E, por fim, o Eixo IV, Experiência como Filha, apresenta uma análise sobre a relação das mulheres, na posição de filhas, com suas mães e seus pais, especilamente após eles terem se tornado avós

\section{Experiência como avó}

O tornar-se avó, de uma forma geral, era uma expectativa que havia se realizado para quase todas as avós entrevistadas, as quais relataram que o momento em que souberam que iam ser avós foi maravilhoso e muito aguardado: "saber que ia ser avó foi a melhor coisa porque me deu um ânimo, sabe?”.

Nove avós relataram que na ocasião de se tornarem avós já estavam pensando na idéia, inclusive achavam que já estavam na idade de ser avós. Duas relataram que a notícia foi uma surpresa, pois não estavam esperando ser avós naquele momento, embora já pudessem se imaginar neste papel. As mesmas duas avós demonstraram que o recebimento da notícia foi um momento de decepção, pois não achavam que a filha devesse ser mãe ainda. Isto sugere que o momento de receberem a notícia de que vão se tornar avós, de confronto com a realidade, pode não ser muito agradável para algumas.

Ao se tornarem avós, algumas já tinham uma idéia de como seria, que era como haviam imaginado, ou até melhor do que haviam imaginado: "eu sempre digo que a melhor coisa do mundo é ser avó”, sendo que para duas delas era melhor do que ser mãe:

\footnotetext{
"é melhor que ser pai e mãe, eu acho que é melhor porque a gente talvez esteja menos preocupada que a mãe... Eu só sei que ser mãe é como uma gostosa torta, e ser avó é uma gostosa torta com chantily em cima”.
}

Alguns temas surgiram quando as avós falavam sobre o seu papel de avó e o seu significado. O ser avó foi citado como sendo algo renovador, que os netos vinham para preencher um vazio experenciado pela idade: “ser avó é renascer.. é ter mais ânimo de vida; tava muito pra baixo e renovou tudo de novo; ele recarrega as minhas forças".

Chama a atenção que das 11 avós entrevistadas, nove relataram não ter tido um modelo de avó a seguir: "tive dois modelos péssimos de avó... mas sempre soube que ser avó, ter avó era uma coisa maravilhosa, eu não tinha boas avós; já vem com a gente”. Essas avós que não tiveram suas avós como modelo procuravam resgatar com os netos as vivências que não tiveram.

\section{Experiência como mãe}

Um dos aspectos que se destacou em todas as entrevistas foi que o nascimento do neto fez com que as avós se lembrassem dos nascimentos de suas filhas: "eu revivi tudo, contava pra ela (filha) como foi e pegava ele (neto) e parecia que tava pegando ela (filha), eu revivi o passado”. Elas relataram que, após verem o neto, o compararam com suas filhas no momento em que nasceram, e também revivenciaram os próprios partos e as dificuldades por que passaram. Para elas, foi um momento de muita emoção, em que "parece que passa um filme" de suas vidas.

Com exceção dos casos que tinham seus maridos doentes para cuidar, todas as outras avós relataram ter ajudado a filha nos primeiros cuidados ao neto. Elas contam que ajudaram o máximo que podiam, a maioria delas tendo ficado na casa das filhas por alguns dias, dando uma assistência em tempo integral a elas e aos netos: "eu sempre deixava pra ela tomar as decisões, mas sempre ajudando ela, dando apoio nas inseguranças dela”. As duas avós que não puderam acompanhar os primeiros dias dos netos relataram ter se sentido frustradas, tristes, pois gostariam de ter podido ajudar, e reconheceram que neste momento a ajuda das mães era muito importante: "e eu tenho assim, um complexo de culpa, uma dor de eu não ter podido ficar lá”.

Todas as mulheres entrevistadas relataram ter acompanhado de uma forma muito próxima a gestação de suas filhas. Elas contaram que se preocupavam com a alimentação da filha, a acompanhavam nas consultas médicas e ecografias, faziam companhia enquanto o genro estava trabalhando e também gostavam de ajudar na compra do enxoval do bebê.

As avós compararam seu papel de avó com o papel de mãe, quando tinham os filhos pequenos. Sete delas referiram que hoje são avós diferentes do que foram mães com filhos pequenos: "eu sou uma mãe mais doce com os netos". Todas referiram que na época em que os filhos eram pequenos trabalhavam muito e não tinham tempo para se dedicar aos 
filhos, especialmente brincar com eles. Hoje, como têm mais tempo livre podem aproveitar mais o tempo com os netos, brincando. Outro ponto destacado foi o tipo de brincadeira, sendo que quase todas estas sete avós relataram que atualmente têm mais disposição e colocam-se na posição da criança, brincando "no chão" com elas, coisa que não faziam com os filhos. O que elas acharam que continua semelhante ao modo como foram mães e como são avós é o carinho e amor dispensado a eles, os cuidados necessários, como higiene e alimentação, fazer a comida que gostam, "fazer as vontades", pôr limites, contar histórias.

Também foi relatado que na época em que a filha era pequena, algumas das atuais avós trabalhavam demais e hoje querem dar aos netos tudo que não puderam dar à filha: "eu reconheço que tudo que eu não pude fazer pela filha eu não deixei isso acontecer com a neta". As avós relataram que hoje têm mais tempo para os netos do que tinham para os filhos quando eram pequenos e que a mãe ou a sogra, ou seja, as avós de seus filhos é que faziam com seus filhos o que hoje elas fazem com os netos: "o que eu to fazendo hoje a minha mãe fazia e eu dizia pra não fazer todas as vontades, ela dizia deixa, a mesma coisa eu digo agora pra minha filha".

As avós também falaram sobre o seu relacionamento com as filhas que lhe deram o primeiro neto ou neta. Algumas delas relataram que sempre tiveram bons relacionamentos com elas, sendo enfatizada a grande proximidade que existe com a filha: "ela é mãe, é amiga, é filha, é vó, é pai, é tudo, a gente é muito amiga". Por outro lado, algumas relataram ter tido um relacionamento conflituoso com a filha durante sua adolescência. Todas elas caracterizaram seu relacionamento atual com a filha como bom ou muito bom. Também foi citado que o relacionamento com a filha melhorou após sua filha ter se tornado mãe: "a filha comigo melhorou, ela se tornou mais preocupada comigo; ela ficou mais madura porque depois que a gente se torna mãe, a gente amadurece, até valoriza mais a mãe depois".

De acordo com 10 avós, as filhas as consideravam boas avós e não interferiam no seu relacionamento com os netos: "eи faço o que eи quero, se eu quero pegar pra sair eu telefono, e também o que eu faço com ele durante o dia ela não liga".

Para nove avós, há uma diferença no envolvimento com o neto por parte das avós maternas e paternas. Elas acham que há uma proximidade maior delas com os netos, vêem os netos com mais freqüência, além de acharem que são mais envolvidas:

\footnotetext{
"a outra vó não se importa, ela não se envolve assim se eles têm ou se não têm alguma coisa, se elas tomaram banho ou não, se elas mamaram ou não, se tá doente. Eu todo dia se eu não vou lá eu ligo".
}

\section{Experiência como neta}

Algumas avós não conviveram com os avós maternos, outras com os paternos. Apesar dos diferentes tipos de convivência, havia em comum um sentimento de que eles eram distantes. Pode ser esta a razão pela qual a maioria das avós disse que a forma como são avós é diferente do modo como seus avós eram com elas quando tinham a idade que seus netos têm hoje: "antigamente não faziam o que a gente faz hoje em dia porque naquela época eram mais rígidos, bem diferente". Todas relataram que seus avós eram mais severos e enérgicos com elas, e algumas acrescentaram que não eram carinhosos, nem tinham uma proximidade com elas: "a gente não podia chegar nem perto, eu me lembro que a minha vó materna ia lá em casa era como se fosse uma santa, nós beijávamos a mão dela".

Algumas avós contaram que com os netos voltaram a ser crianças, ou que ao serem avós estavam sendo netas novamente, sendo as avós que não tiveram: "na verdade eu tava querendo ser neta de novo, pois eu não tive avó"; "eu faço tudo o que eles não faziam, acho que é pra compensar". Estes dados mostram que o tornar-se avó faz reviver não apenas a experiência como mãe, mas também as vivências infantis como neta.

\section{Experiência como filha}

Ao comparar o modo de serem avós com a forma como seus pais foram avós de seus filhos, quando estes tinham a idade de seus netos, sete delas relataram que são diferentes: "é como se diz aquela plantinha que tu vai regando vai crescencdo, eu penso que não é que eles não tivessesm amor pra dar, mas de repente não tinham tempo pra cultivar".

Para nove avós entrevistadas, o relacionamento com o pai e a mãe, antes de serem mães, era bom, sendo que para algumas delas melhorou após o nascimento do neto: "é como se faltasse alguma coisa, um elo pra aquele relacionamento, o que veio com o meи neto". Mas para as outras seis entrevistadas, o relacionamento com o pai e a mãe permaneceu igual. Algumas avós passaram a valorizar mais os pais por tudo que eles passaram por elas: "eu passei a reconhecer, valorizar mais a minha mãe, tudo que ela se doou, acho que aconteceu com todas as filhas".

\section{Discussão}

Ao investigar o momento do tornar-se avó, oportunizou-se que as avós reflletissem sobre o seu papel de avós e sobre os outros papéis que exerceram e ainda têm exercido ao longo de suas vidas. Antes de serem avós, foram filhas, netas e mães. Como filhas desenvolveram uma relação particular com seus pais, uma forma de relacionar-se que trazem consigo, como uma bagagem, e que as permitiu apreender um modelo de relacionar-se com os outros. $\mathrm{E}$, independentemente ou não desta relação, tiveram outra com seus avós, que também deixou marcas e expectativas de como uma avó deve ser. Como mães também puderam desenvolver outra relação e experimentar um novo papel, diferente dos que já haviam vivido.

A primeira individuação se deu enquanto ainda eram crianças, à medida que foram se diferenciando da mãe (Mahler, 1982). Na adolescência, tiveram seus conflitos típicos da idade, em busca de sua autonomia, o que as proporcionou a segunda individuação (Blos, 1994). Ao se tornarem mães, na terceira individuação (Colarusso, 1990), uma nova estrutura psíquica se formou, em que uma relação de intimidade gerou um filho. Nesse momento, presenciaram a construção de um novo papel, para seus pais, em que estes exerceram a função de avós. Aqui já houve um confronto 
entre o que elas assimilaram de um relacionamento entre avós e netos, através de sua relação com seus avós, e seus próprios pais como avós.

Por se tornarem mães, também puderam colocar-se no lugar de suas mães, e essa experiência as forneceu a oportunidade de compreendê-las. Uma nova relação surgiu, com seus descendentes, em que experenciaram seu papel de mãe, alternando momentos prazerosos e momentos difíceis. Mais tarde, quando já na meia-idade, outra mudança, o tornar-se avó, oportunizou que elas reavaliassem sua vida, caracterizando a quarta individuação (Colarusso, 1990, 1997, 2000). Puderam, assim, estabelecer uma nova relação com outra criança, amparada em laços co-sangüíneos, sendo assegurada a sua continuidade genética. Os resultados do presente estudo mostraram que, apesar das peculiaridades de cada avó, todas experenciaram uma reflexão sobre suas vidas, seus papéis, seus relacionamentos. Hoje, após anexarem esta experiência a suas vidas, tornaram-se pessoas diferentes, com outros propósitos e outras resoluções para antigos conflitos. O contato com os netos permitiu que se renovassem os vínculos com suas filhas, suas mães, e com suas avós. Uma nova constelação familiar se formou, e novos papéis se agregaram aos já existentes, inaugurando uma nova etapa de vida, reorganizando a identidade feminina.

De acordo com Carter e McGoldrick (2001), em cada fase do ciclo de vida familiar há tarefas específicas a serem resolvidas, mas em cada ponto de transição os antigos conflitos, que não foram solucionados, têm novamente uma chance de se desfazer. Assim como ao se tornar pai e mãe, ao se tornar avô e avó há uma possibilidade de elaboração de conflitos anteriores. Colarusso (1997) aponta a transição para o tornar-se avó como um destes momentos em que os conflitos ressurgem e em que, através dos netos, conflitos com os filhos, com os pais, e consigo mesmo, podem ser reelaborados, caracterizando-se o que o autor denomina a quarta individuação.

O presente estudo traz evidências sobre o ressurgimento de questões infantis e da tentativa de elaboração das mesmas no tornar-se avós. Assim, pode-se concluir que estas questões são reativadas não apenas pela parentalidade, como destacam alguns autores que trabalham com o desenvolvimento emocional (Brazelton \& Cramer, 1992), mas ressurgem no tornar-se avó, caracterizando a quarta individuação. O filho representa uma promessa de realização de desejos infantis, tais como o desejo de onipotência e completude, de simbiose e fusão, de realização de ideais e oportunidades perdidas, de renovação de antigos vínculos. O neto representa uma segunda chance de reparação das experiências infantis e de superação dos pais, na medida em que os avós podem imaginar que agora com o neto finalmente irão conseguir realizar os desejos que não puderam ser realizados com seus próprios pais, na posição de filhos, com seus avós, na posição de netos, ou com seus filhos na posição de pais. No presente estudo, todas as avós relataram que quando seus filhos eram pequenos, tinham que trabalhar e não tinham muito tempo para brincar com eles, por exemplo. Desta forma, procuravam resgatar com os netos a vivência que não puderam ter com os filhos e proporcionar a eles tudo o que não puderam dar aos filhos. Os resultados do presente estudo mostraram ainda que o nascimento do neto representa, para muitas avós, o seu próprio renascimento, e uma nova chance de realização de oportunidades perdidas. Ou seja, o neto tem o poder de reavivar nos avós seus desejos, sonhos, ideais que não puderam ser realizados.

Com relação ao desejo de fusão, os avós têm a experiência de perda dos filhos, devido ao crescimento destes, mas o desejo de fusão pode ser alimentado pelos netos, contrapondo-se aos sentimentos negativos de perda (Colarusso, 2000). O sentir-se fusionado com o neto apareceu no relato de algumas avós, assim como a percepção de que o neto era como um filho.

O desejo narcísico de completude, que surge com a parentalidade (Brazelton \& Cramer, 1992), também pode se evidenciado nas avós. No presente estudo, o nascimento do neto trouxe para as avós lembranças do nascimento das próprias filhas, sendo que o momento do parto das filhas representou uma reconstrução de seus próprios partos. Os relatos mostraram que há uma recordação quase fiel do dia do nascimento das filhas, com uma riqueza de detalhes e identificações com o momento atual, em que a filha repetia a mesma situação das mães. Assim, o mesmo sentimento de estar se completando é revivido, integrando tempos distantes, mas que têm muito em comum. Muitas avós também relataram que os netos vieram preencher um vazio provocado, entre outras coisas, pela saída da filha de casa, evidenciando, uma vez mais, o desejo de completude.

A relação da nova avó com a própria filha que se torna mãe é fortalecida com estes novos acontecimentos e surgimento de novos papéis (Barros, 1987). A filha é vista de uma forma mais madura pela mãe, pois o sofrimento de tornar-se mãe provoca uma identificação entre as duas gerações, e a filha adulta é reconhecida como tal. Para Colarusso (1997), a autonomia dos filhos estimula a independência dos pais.

Uma das questões que chamou a atenção foi o fato de que a maioria das avós não teve modelos de avós. Na entrevista utilizada no presente estudo, tinha-se uma questão sobre onde buscaram os modelos de avós, se na própria infância, com os avós, ou já na vida adulta, com os pais sendo avós de seus filhos. As participantes do estudo relataram que no tempo em que eram crianças, os avós eram mais distantes emocionalmente e a relação dos netos com os avós era formal. A vivência dos próprios pais como avós também não serviu como modelo. Para Bowen (1991), autor da abordagem familiar sistêmica, o processo de individuação consiste na tentativa de diferenciação em relação à família de origem. Desta forma, ao refletir sobre seu papel de avó, comparado à forma como seus pais foram avós, a avó está diferenciando-se deles, e construindo seu modo particular de vivenciar este papel. Pode-se concluir que o tornar-se avó propicia uma reflexão e uma construção particular do que é ser avó, e embora os avós e os pais não sirvam como modelos perfeitos, são sempre um modelo de referência, mesmo ao desejarem ser avós diferentes.

Para finalizar, espera-se que este estudo tenha contribuído para compreender o tornar-se avó como um importante marco evolutivo do desenvolvimento adulto, pouco abordado nos estudos sobre avós. $\mathrm{O}$ foco no processo de individuação é especialmente importante e praticamente ignorado pela literatura, podendo contribuir para um melhor entendimento dos aspectos emocionais envolvidos no processo de tornar-se 
avó. Uma limitação do estudo consiste no fato de a coleta de dados ter sido realizada em um único momento, em que os netos estavam com 3 ou 4 anos de idade. Estudos futuros poderiam acompanhar, através de delineamento longitudinal, o tornar-se avó desde o período gestacional da filha, possibilitando, assim, melhor apreender o desenrolar dos processos evolutivos na avó. Sugere-se, também, que estudos futuros possam investigar as avós paternas, bem como os avôs maternos e paternos, com o intuito de analisar as suas peculiaridades.

\section{Referências}

Bardin, L. (1977). Análise de conteúdo. Lisboa: Edições 70.

Barros, M. L. (1987). Autoridade e Afeto. Avós, filhos e netos na família brasileira. Rio de Janeiro: Jorge Zahar.

Blos, P. (1994). Transição Adolescente. (M. R. Hofmeister, Trad.). Porto Alegre: Artes Médicas. (Trabalho original publicado em 1979)

Bowen, M. (1991). De la familia al individuo. (B. E. A. de Lonné, Trad.). Buenos Aires: Paidos. (Trabalho original publicado em 1979)

Brazelton, T. B. \& Cramer, B. G. (1992). As Primeiras Relações. (M. B. Cippola, Trad.). Porto Alegre: Artes Médicas. (Trabalho original publicado em 1990)

Carter, B. \& McGoldrick, M. (2001). As Mudanças no ciclo de vida familiar. Uma estrutura para a terapia familiar. (2 ed) (M. A. V. Veronese, Trad., 2 ed.). Porto Alegre: Artes Médicas. (Trabalho original publicado em 1989)

Colarusso, C. A. (1990). The Third Individuation. The Effect of Biological Parenthood on Separation-Individuation Processes in Adulthood. Psychoanalityc Study of the Child, 45, 179-194.

Colarusso, C. A. (1997). Separation-Individuation Process in Middle Adulthood: The Fourth Individuation. Em S. Akhtar \& S. Kramer (Orgs.), The Seasons of Life: Separation-Individuation Perspectives (pp. 73-94). Northvale: Jason Aronson.

Colarusso, C. A. (2000). Separation-Individuation in Adulthood: General Concepts and the Fifth Individuation. Journal of the American Psychoanalitic Association, 48, 1467-1489.
Dias, C. S. B. (1994). A Importância dos Avós no Contexto Familiar. Psicologia: Teoria e Pesquisa, 10(1), 31-40.

Fischer, L. R. (1983). Transition to grandmotherhood. The International Journal of Aging and Human Development, 16, 67-78.

Grupo de Interação Social, Desenvolvimento e Psicopatologia - GIDEP (1998). Consentimento Informado. Universidade Federal do Rio Grande do Sul, Porto Alegre.

Hader, M. (1965). The Importance of Grandparents in Family Life. Family Process, 4, 228-238.

Kipper, C. D. \& Lopes, R. S. (2002). Entrevista com avô e avó. Universidade Federal do Rio Grande do Sul, Porto Alegre.

Laville, C \& Dionne, J. (1999). A Construção do Saber. (H. M. F. Setinneri, Trad.) Porto Alegre: Artes Médicas. (Trabalho original publicado em 1997)

Lidz, T. (1983). A pessoa: seu desenvolvimento durante o ciclo vital. (A. B. Simões, Trad.) Porto Alegre: Artes Médicas. (Trabalho original publicado em 1980)

Mahler, M. (1982). O processo de separação-individuação. (H. M. de Souza, Trad.). Porto Alegre: Artes Médicas. (Trabalho original publicado em 1979)

Piccinini, C. A., Tudge, J. R., Lopes, R. S. \& Sperb, T. M. (1998). Estudo Longitudinal de Porto Alegre: Da Gestação à Escola. Projeto de Pesquisa, Universidade Federal do Rio Grande do Sul, Porto Alegre.

Robinson, L. H. (1989). Grandparenting: Intergenerational Love and Hate. The Journal of the American Academy of Psychoanalysis, 17, 483-491.

Somary, K. \& Stricker, G. (1998). Becoming a Grandparent: A longitudinal Study of Expectations and Early Experiences as a Function of Sex and Lineage. The Gerontologist, 38, 53-61.

Stake, R. E. (1994). Case Studies. Em N. Denzin \& Y. Lincoln (Orgs.), Handbook of Qualitative Research (pp. 236-247). London: Sage.

Recebido em 03.03.2005

Primeira decisão editorial em 11.10.2005

Versão final em 16.12.2005

Aceito em 13.02.2006

\section{NORMAS DE PUBLICAÇÃO}

São adaptadas de Publication Manual of the American Psychological Association (APA, $5^{\text {a }}$ Edição, 2001) e podem ser consultadas ao final de cada número (versão impressa ou online) ou no sítio: http://www.revistaptp.org.br 